\title{
Estimations of Heritability and Breeding Value for Postharvest Fruit Softening in Apple
}

\author{
Hiroshi Iwanami ${ }^{1}$, Shigeki Moriya, Nobuhiro Kotoda, Sae Takahashi, and Kazuyuki Abe \\ Apple Breeding and Physiology Research Team, National Institute of Fruit Tree Science, \\ Shimo-kuriyagawa, Morioka 020-0123, Japan
}

\begin{abstract}
AdDitional INDEX WORDs. Malus $\times$ domestica, general combining ability, specific combining ability, firmness, mealiness
Abstract. Progenies from 38 unbalanced crosses using 20 apple (Malus $\times$ domestica Borkh.) cultivars/selections as parents were evaluated for changes in flesh firmness after harvest in two seasons to determine the mechanism of inheritance of fruit softening. The change in firmness was fitted by linear regression, and the softening rate $\left(N \cdot d^{-1}\right)$ expressed as the regression coefficient was used as the phenotypic value of softening after harvest. Fruit were stored under $20{ }^{\circ} \mathrm{C}$ and $85 \%$ relative humidity after harvest for up to 40 days. The softening rates in the progeny populations were distributed continuously around the softening rates of parents, despite a distinct segregation in the degree of mealiness at 30 days of storage. The narrow-sense heritability of the softening rate was estimated by parent-offspring regression, and the estimate was high $\left(h^{2}=0.93\right)$. Because the softening rate can be influenced by mealiness, an undesirable trait in the apple industry, the progenies were divided into individuals with and without mealiness, and the breeding values of the parents were estimated based on the softening rate of the nonmealy progeny. The softening rate of the nonmealy progeny was analyzed using a mixed linear model and the restricted maximum likelihood method, with general combining ability (GCA) as parental effects and specific combining ability (SCA) as parental interaction effects. The variance of GCA was significant, but the variance of SCA was small and nonsignificant. The narrow-sense heritability of the softening rate in the nonmealy progeny was estimated by sib analysis, and the estimate was moderately high $\left(h^{2}=0.55\right)$. A significant correlation was observed between the phenotypic value and the breeding value (twice the GCA effects) in nonmealy parents, but the phenotypic value did not significantly correlate with the breeding value in mealy parents. Therefore, contribution of a mealy parent to the softening rate of nonmealy progenies cannot be predicted by its phenotypic value.
\end{abstract}

A major quality problem with apples in the marketplace is fruit softening (Johnston et al., 2002a). The degree or rate of softening after harvest depends on the cultivar (Iwanami et al., 2004). Although 'Fuji' and 'Honeycrisp' maintain their firmness long after harvest and have good storage capability (Tong et al., 1999; Yoshida et al., 1998), the fruit of 'Red Delicious' and 'Golden Delicious' become mealy (Hampson and Kemp, 2003) and soften rapidly when harvested late. Softening has not been sufficiently evaluated among commercial cultivars, and, at times, it is not considered as a trait for selection in apple breeding, although a cultivar in which the fruit hardly softens is advantageous to the apple market and industry. Crosses between commercial cultivars with good eating quality can produce progenies with varying rates and degrees of softening. To produce a new cultivar with good storage and shelf life potential, it is useful to determine genotypic differences in and mechanism of inheritance of fruit softening.

Resemblance among relatives is a basic genetic phenomenon, and the degree of resemblance determines heritability, which in turn facilitates the choice of a breeding method for use in genetic improvement (Falconer and Mackay, 1996). The estimation of the degree of resemblance for fruit softening after harvest, however, has received little attention in apple breeding because there is no effective phenotypic value or index for fruit softening upon which to compare relatives. Fruit softening is generally expressed as the decrease in firmness after storage. Apples soften by $25 \%$ to $50 \%$ of their firmness at harvest, and the final firmness depends on the cultivars (Johnston et al., 2002a). Furthermore, firmness does not always continue to

Received for publication 2 July 2007. Accepted for publication 5 Oct. 2007. ${ }^{1}$ Corresponding author. E-mail: hiwanami@affrc.go.jp. decrease during storage (Iwanami et al., 2004), and the degree and period of decrease vary widely among cultivars. Johnston et al. $(2001,2002 \mathrm{~b})$ proposed a nonlinear regression model to fit the change in firmness during storage and to compare cultivars on degree and rate of softening based on a parameter (e.g., the rate of change in firmness) in the model. However, the model can estimate the parameter only when a rapid reduction in firmness is observed after harvest and it requires that a large number of fruit samples be used to estimate the parameter. The model, therefore, does not lend itself to breeding situations because apple seedlings do not always bear a sufficient number of fruit for storage tests or display rapid reduction in fruit firmness after harvest.

To evaluate differences in the softening of apple genotypes, Iwanami et al. (2004) proposed a linear regression model to fit the change in firmness during storage. The regression coefficient measures the softening rate and can be estimated from a limited number of harvested fruit in breeding situations. Iwanami et al. (2005a) also indicated that, although the estimate of the parameter was influenced by environmental factors such as year, tree, and sampling date, the magnitudes of the influence were relatively small, and the estimate was considered to be stable against environmental conditions. The linear regression coefficient, therefore, can be a useful index for comparing relatives as the phenotypic value of softening after harvest.

Changes in firmness after storage can also be influenced by mealiness (Iwanami et al., 2005b). A high degree of mealiness occurred in 7 of 24 cultivars tested and the softening rates of the mealy cultivars were all high, with about the same values (Iwanami et al., 2005b). These findings indicate that if a cultivar in which mealiness occurs produces progeny in which mealiness does not occur, the softening rate of the progeny cannot 
be predicted from the softening rate of the parent cultivar because the softening rate (phenotypic value) of the parent is affected by mealiness, which is not inherited by the progeny. To determine the contribution of a mealy parent to the softening rate of its nonmealy progeny, the estimation of the breeding value of the mealy parent is necessary.

Narrow-sense heritability or combining ability has been estimated to improve breeding strategies and to evaluate the potential of cultivars for use as parents in fruit breeding programs for several quantitative traits in blueberry (Vaccinium L.; Finn and Luby, 1992), grape (Vitis L.; Firoozabady and Olmo, 1987), Japanese quince [Chaenomeles japonica (Thunb.) Lindl. ex Spach] (Rumpunen and Kviklys, 2003), kiwifruit [Actinidia deliciosa (A. Chev.) C.F. Liang \& A.R. Ferguson] (Daoyu et al., 2002), peach [Prunus persica (L.) Batsch] (de Souza et al., 1998; Hansche et al., 1972), and sweet cherry [Prunus avium (L.) L.] (Hansche et al., 1966). However, genetic parameters have not been determined for storage potential. Other than the estimation of the heritability of several storage disorders in apple by Volz et al. (2001), genetic parameters have rarely been determined for fruit storage potential. The objectives of the current study were to estimate the heritability and the breeding value for apple fruit softening to facilitate the selection of new cultivars with good storage potential in apple breeding programs.

\section{Materials and Methods}

Progeny population. This study was carried out using progeny from the apple breeding program at the National Institute of Fruit Tree Science (NIFTS), Morioka, Japan. Twenty cultivars/selections (genotypes) were used as parents
(Table 1). The genotypes consisted of four cultivars ('Jonathan', 'Raritan', 'Starking Delicious', and 'Golden Delicious') from North America and 14 cultivars and two selections (Morioka 54 and Morioka 57) from Japan. The progeny populations consisted of 40 families, with 10 to 100 individuals per family. Among the 40 families, 22 and 35 were chosen in 2004 and 2005, respectively, for storage tests, whereas 17 were evaluated in both years (Table 2). However, not every tree produced fruit in each year; therefore, between 2 and 47 progenies per family and a total of 614 progenies were used for fruit analysis. There were two reciprocal crosses, but the progenies of the reciprocal crosses were combined for analysis because each of the reciprocal crosses had only a few progenies. Crosses were made solely for producing commercial cultivars and, therefore, had no specific mating design. As a result, the frequency of use of a cultivar in crosses differed greatly among parental genotypes. For example, 'Fuji' was used in 11 crosses, whereas 'Raritan', 'Golden Delicious', 'Akagi', and Morioka 57 were used in only one cross each. Progenies were grafted onto 'JM7' dwarfing rootstocks and were planted in 2000 to 2002 in an orchard. Trees within a family were planted beside each other at a spacing of $0.5 \mathrm{~m}$ within a row with $3 \mathrm{~m}$ between rows. Parental plants were grown in adjacent fields.

Fruit materials. Depending on the number of fruit on a tree, 25 to 40 fruit samples were randomly harvested from a tree of each parental genotype one to three times weekly during the maturity period, which was determined by sensory evaluations based on ground color, texture, flavor, and starch staining in 2004 and 2005. The number of fruit on a tree of each progeny was limited, and 7 to 25 fruit were harvested at one time when most of the fruit was judged to be mature by the sensory evaluations in progeny populations.

Table 1. Fruit softening rate, degree of mealiness at $30 \mathrm{~d}$ of storage at ambient conditions, and general combining ability (GCA) for softening rate (estimated from nonmealy progeny only) in 20 parental apple genotypes.

\begin{tabular}{|c|c|c|c|c|c|}
\hline Cultivar/selection & Rootstock & Treeage $^{z}$ & $\begin{array}{l}\text { Fruit softening } \\
\text { rate }\left(\mathrm{N} \cdot \mathrm{d}^{-1}\right)\end{array}$ & $\begin{array}{c}\text { Degree of } \\
\text { mealiness }(\%)\end{array}$ & $\mathrm{GCA} \pm \mathrm{SE}$ \\
\hline \multicolumn{6}{|l|}{ Nonmealy genotypes } \\
\hline Morioka 57 & M.26E & Unknown & $2.0^{\mathrm{y}}$ & $6^{\mathrm{y}}$ & $0.09 \pm 0.28$ \\
\hline Tsugaru & JM7 & 8 & 1.9 & 3 & $0.12 \pm 0.17$ \\
\hline Jonathan & Marubakaido & 46 & 1.7 & 7 & $-0.06 \pm 0.22$ \\
\hline Orin & M.9 & 10 & 1.7 & 7 & $-0.11 \pm 0.21$ \\
\hline Hatsuaki & Jonathan/Marubakaido & (6) & 1.3 & 2 & $-0.02 \pm 0.22$ \\
\hline Megumi & Unknown & Unknown & 1.2 & 4 & $0.14 \pm 0.18$ \\
\hline Akagi & M.26E & Unknown & 1.1 & 0 & $-0.20 \pm 0.25$ \\
\hline Kotaro & JM2 & 14 & 0.8 & 7 & $-0.25 \pm 0.18$ \\
\hline Shinsekai & M.26E & Unknown & 0.8 & 1 & $-0.26 \pm 0.21$ \\
\hline Morioka 54 & Unknown & Unknown & 0.6 & 0 & $-0.13 \pm 0.21$ \\
\hline Senshu & JM7 & 11 & 0.2 & 0 & $-0.17 \pm 0.16$ \\
\hline Kitaro & JM7 & 14 & 0.2 & 0 & $-0.16 \pm 0.21$ \\
\hline Fuji & JM7 & 23 & 0.0 & 0 & $-0.49 \pm 0.15$ \\
\hline \multicolumn{6}{|l|}{ Mealy genotypes } \\
\hline Raritan & Unknown & Unknown & 3.8 & 33 & $0.47 \pm 0.28$ \\
\hline Akane & Jonathan/Marubakaido & (6) & 3.1 & 30 & $0.20 \pm 0.16$ \\
\hline Himekami & M.26E & Unknown & 2.6 & 33 & $-0.10 \pm 0.25$ \\
\hline Starking Delicious & MM.106 & 32 & 2.6 & 53 & $0.38 \pm 0.18$ \\
\hline Sansa & M.26E & 18 & 2.3 & 51 & $0.67 \pm 0.15$ \\
\hline Golden Delicious & M.9 & 10 & 1.6 & 36 & $-0.21 \pm 0.28$ \\
\hline Toko & Unknown & Unknown & 1.5 & 41 & $0.11 \pm 0.26$ \\
\hline
\end{tabular}

${ }^{\mathrm{z}}$ Numeral in parenthesis indicates years since top-grafting on intermediate stock.

${ }^{\mathrm{y}}$ Mean value of the measurements obtained from each fruit sample harvested one to three times weekly for 2 years. 
Table 2. The proportion of progeny with nonmealy fruit in 38 apple families.

\begin{tabular}{|c|c|c|c|c|c|c|c|}
\hline \multirow[b]{2}{*}{ Cross } & & & \multicolumn{3}{|c|}{ Progeny evaluated (no.) in } & \multirow{2}{*}{$\begin{array}{c}\text { Progeny } \\
\text { evaluated } \\
\text { (no.) }\end{array}$} & \multirow{2}{*}{$\begin{array}{c}\text { Nonmealy } \\
\text { progeny } \\
(\text { no. })^{z}\end{array}$} \\
\hline & & & 2004 & 2005 & Both years & & \\
\hline Fuji & & Morioka 54 & & 15 & & 15 & 13 \\
\hline Fuji & $\times$ & Kotaro & & 14 & & 14 & 13 \\
\hline Senshu & $\times$ & Morioka 54 & & 12 & & 12 & 6 \\
\hline Kitaro & $x$ & Shinsekai & & 8 & & 8 & 7 \\
\hline Senshu & $x$ & Shinsekai & 11 & 13 & 11 & 13 & $12(10)$ \\
\hline Senshu & $\times$ & Kotaro & & 29 & & 29 & 25 \\
\hline Akagi & $\times$ & Fuji & 12 & & & 12 & 11 \\
\hline Fuji & $\times$ & Megumi & 16 & 16 & 14 & 18 & $16(12)$ \\
\hline Fuji & $x$ & Hatsuaki & 4 & & & 4 & 4 \\
\hline Fuji & $\times$ & Orin & & 3 & & 3 & 3 \\
\hline Fuji & $\times$ & Tsugaru & & 38 & & 38 & 38 \\
\hline Fuji & $\times$ & Morioka 57 & 6 & 1 & 1 & 6 & $4(0)$ \\
\hline Kitaro & $\times$ & Tsugaru & & 3 & & 3 & 2 \\
\hline Toko & $\times$ & Morioka 54 & & 5 & & 5 & 3 \\
\hline Tsugaru & $\times$ & Senshu & 6 & & & 6 & 5 \\
\hline Toko & $\times$ & Kotaro & & 7 & & 7 & 3 \\
\hline Fuji & $\times$ & Sansa & 4 & 15 & 4 & 15 & $12(4)$ \\
\hline Senshu & $\times$ & Sansa & 15 & 13 & 10 & 18 & $9(7)$ \\
\hline Hatsuaki & $\times$ & Megumi & & 30 & & 30 & 26 \\
\hline Fuji & $\times$ & Starking Delicious & 12 & 12 & 9 & 15 & $10(7)$ \\
\hline Fuji & $\times$ & Himekami & & 2 & & 2 & 2 \\
\hline Senshu & $\times$ & Himekami & & 8 & & 8 & 5 \\
\hline Fuji & $\times$ & Akane & 7 & 7 & 5 & 9 & $8(4)$ \\
\hline Sansa & $\times$ & Shinsekai & 7 & 11 & 6 & 12 & $2(0)$ \\
\hline Kitaro & $\times$ & Akane & & 47 & & 47 & 26 \\
\hline Senshu & $\times$ & Akane & 8 & 9 & 8 & 9 & $7(6)$ \\
\hline Kotaro & $\times$ & Akane & 13 & & & 13 & 5 \\
\hline Orin & $\times$ & Sansa & 4 & 4 & 3 & 5 & $4(2)$ \\
\hline Jonathan (Sansa) & $x$ & Sansa (Jonathan) & & 27 & & 27 & 8 \\
\hline Tsugaru (Sansa) & $\times$ & Sansa (Tsugaru) & & 18 & & 18 & 8 \\
\hline Akane & $x$ & Megumi & 16 & 16 & 11 & 21 & $10(6)$ \\
\hline Jonathan & $\times$ & Starking Delicious & 12 & 15 & 10 & 17 & $7(4)$ \\
\hline Tsugaru & $\times$ & Starking Delicious & 26 & 37 & 26 & 37 & $14(11)$ \\
\hline Golden Delicious & $x$ & Akane & 7 & & & 7 & 4 \\
\hline Akane & $x$ & Orin & 7 & 10 & 6 & 11 & $6(3)$ \\
\hline Sansa & $\times$ & Starking Delicious & 26 & 37 & 24 & 39 & $4(1)$ \\
\hline Sansa & $\times$ & Akane & 9 & 22 & 8 & 23 & $5(2)$ \\
\hline Sansa & $\times$ & Raritan & 21 & 32 & 18 & 35 & $3(1)$ \\
\hline Total & & & 252 & 536 & 174 & 614 & $353(80)$ \\
\hline
\end{tabular}

${ }^{\mathrm{z}}$ Numbers of nonmealy progenies evaluated in both years are presented in parentheses.

Fruit Softening EVAluation. Firmness measurements on individual fruit were subjected to linear regression analysis. The linear regression for a change in firmness was determined from the harvest date until firmness decreased by $20 \%$ of the harvest value, as described by Iwanami et al. (2004). The regression coefficient was defined as the softening rate (Newtons per day). Phenotypic differences for a change in firmness during storage were evaluated by comparing the softening rate.

Statistical analysis. Analysis of variance (ANOVA) was performed for the softening rates of individual progenies that were sampled in both years to evaluate the effect of year on family mean. The softening rates of all progenies were then analyzed using the following mixed linear model:

$$
\begin{aligned}
Y_{i j k l}= & \mu+Y_{r_{i}}+G_{j-m}+G_{k-f}+S_{j k} \\
& +e_{i j k l}
\end{aligned}
$$

where $Y_{i j k l}$ is the softening rate of the lth progeny from a cross between the jth male parent and the kth female parent in ith year; $\mu$ is the overall mean; $\mathrm{Yr}_{\mathrm{i}}$ is the fixed effect of ith year; $G_{j-m}$ and $G_{k-f}$ are the random effects of the jth male parent and the kth female parent, respectively, which are analogous to the GCA of the jth and kth parents; $S_{j k}$ is the random effect of the jth and kth parent interactions, which is analogous to the SCA; and $\mathrm{e}_{\mathrm{ijkl}}$ is the residual term indicating the withinfamily deviation resulting from the effects of the lth progeny of family $\mathrm{jk}$. The estimation of the variance components of the random effect in

Storage Conditions. One to five fruit from each harvested sample were used for the measurements of flesh firmness and mealiness at harvest and thereafter, at 5- or 10-d intervals until $40 \mathrm{~d}$ after harvest. Apples were stored in 25-L containers arranged on racks in a chamber controlled at $20{ }^{\circ} \mathrm{C}$ and $85 \%$ relative humidity. Fruit with rots were immediately removed from the containers during storage upon visual detection.

MEASUREMENT OF FLESH FIRMNESS AND MEALINESS. Flesh firmness was measured using a penetrometer (FT327; McCormick Fruit Technology, Yakima, WA) mounted on a drill press and fitted with an 11.1-mm probe on the pared surfaces of the sunny and shady sides of each fruit. Mealiness was measured according to Iwanami et al. (2005b). It was a flesh disc sucrose infiltrate and shake method: the degree (percentage) of mealiness was determined by the difference between the weights of flesh discs before and after shaking in a sucrose solution. this model was based on restricted maximum likelihood (REML) in SAS (SAS Institute, Cary, NC) using the MIXED procedure. REML is well suited for unbalanced designs to estimate variance components and can give the variance of male GCA $\left(\sigma_{G C A-m}^{2}\right)$ and female GCA $\left(\sigma_{G C A-f}^{2}\right)$, the variance of $\operatorname{SCA}\left(\sigma_{S C A}^{2}\right)$, and the within-family variance $\left(\sigma^{2}\right)$. The breeding value, however, is generally expressed as twice the GCA, which is defined without distinction between males and females in diallel mating designs. Therefore, according to the methods described by Xiang and Li (2001), dummy variables were constructed for each parent using the IML procedure in SAS to make $\sigma_{G C A-f}^{2}=\sigma_{G C A-m}^{2}=\sigma_{G C A}^{2}$, and a variance component of the GCA effect was estimated. Simultaneously, the GCA effects of each parental genotype were obtained by applying the method of best-linear unbiased prediction (BLUP) in the SAS procedure MIXED to this model. 
The narrow-sense heritability $\left(\mathrm{h}^{2}\right)$ of the softening rate was estimated using parent-offspring regression and sib analysis. Because the covariance of half-sibs was $\mathrm{COV}_{(\mathrm{HS})}=1 / 4 V_{A}=\sigma_{G C A}^{2}$ (where $V_{A}=$ additive genetic variance; Xiang and $\mathrm{Li}, 2001$ ), the narrow-sense heritability was estimated using sib analysis as $h^{2}=$ $V_{A} / V_{P}=4 \sigma_{G C A}^{2} /\left(2 \sigma_{G C A}^{2}+\sigma_{S C A}^{2}+\sigma^{2}\right)$ (where $V_{P}=$ phenotypic variance). The standard error of the heritability estimated by sib analysis was calculated according to Falconer and Mackay (1996).

\section{Results}

Flesh firmness started decreasing immediately after harvest and stopped by $15 \mathrm{~d}$ of storage in all parental genotypes, with few exceptions. The softening rates varied largely among genotypes, from 'Fuji', which did not soften during storage, to 'Raritan', which softened rapidly on a large scale (Table 1). High degrees of mealiness occurred and developed during storage in some genotypes, and little or none was detected in others. The softening rates tended to be larger in genotypes in which mealiness occurred and increased during storage than in genotypes in which mealiness hardly occurred. There were also genotypes in which firmness decreased rapidly but the degree of mealiness was slight. Genotypes could be classified into two groups based on the degree of mealiness at $30 \mathrm{~d}$ of storage: mealy genotypes, in which mealiness occurred and increased above $30 \%$, and nonmealy genotypes, in which mealiness hardly occurred and was below $10 \%$ at $30 \mathrm{~d}$ of storage (Table 1).

The flesh firmness in most progenies decreased rapidly after harvest, and stopped by $20 \mathrm{~d}$ of storage. Mealiness started to be detected at 5 or $10 \mathrm{~d}$ of storage and stopped at $30 \mathrm{~d}$ of storage in many progenies in which mealiness was observed. Segregation of the degree of mealiness at $30 \mathrm{~d}$ of storage in the progeny populations was observed (Fig. 1). The degree of mealiness in most progenies from crosses among nonmealy genotypes (mealiness $<10 \%$ ) was below $20 \%$, but it was more than $50 \%$ in some progenies (Fig. 1A). The degrees of mealiness in progenies from crosses in nonmealy genotypes (mealiness $<$ $10 \%$ ) and mealy genotypes (mealiness $>30 \%$ ) tended to be divided into two groups, one below $15 \%$ and the other over $40 \%$ (Fig. 1, B and C). The degree of mealiness in most progenies from crosses among mealy genotypes (mealiness $>30 \%$ ) was more than $50 \%$ but below $20 \%$ in some progenies (Fig. $1, \mathrm{D}$ and $\mathrm{E})$. Therefore, the occurrence and development of mealiness are considered to involve major genes. When the degree of mealiness at $30 \mathrm{~d}$ of storage was below $20 \%$, the progeny was defined as nonmealy, and when it was more than $20 \%$, it was defined as mealy. The segregation ratios of the progeny population varied among families; all 38 progenies were nonmealy in the 'Fuji' $x$ 'Tsugaru' cross, whereas three of 35 progenies from the 'Sansa' $\times$ 'Raritan' cross were nonmealy (Table 2).

The softening rates in the progeny populations were distributed continuously around the softening rates of parents (Fig. 2). The softening rates of most progenies from crosses among genotypes with softening rates of 0 to 1 were within the same range (Fig. 2A). All progenies with a softening rate of more than 3 from these families were mealy. However, not all mealy progenies had high softening rates, even though mealiness occurred in these low mealiness crosses, as well as others with higher mealiness parents. Some progenies showed 0 to 1 softening rates even though mealiness occurred. In crosses

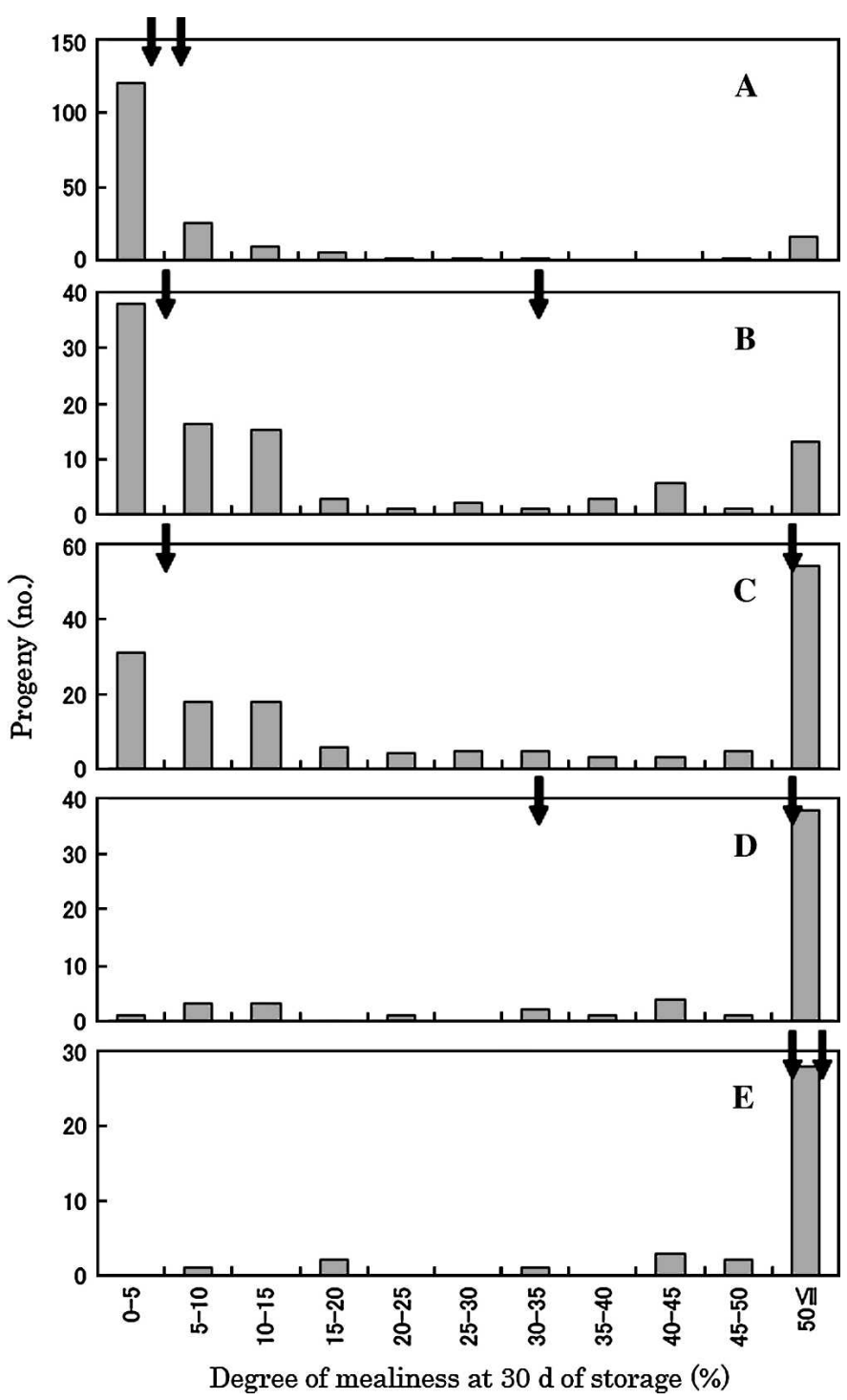

Fig. 1. Frequency distributions of degree of mealiness at $30 \mathrm{~d}$ of storage under ambient conditions in 31 apple families in 2005 . Families were classified into five groups based on the degree of mealiness of the parents. Each group consisted of progenies from (A) 12 crosses ('Fuji' $\times$ Morioka 54, 'Fuji' $\times$ 'Kotaro', 'Senshu' $\times$ Morioka 54, 'Kitaro' $\times$ 'Shinsekai', 'Senshu' $\times$ 'Shinsekai', 'Senshu' $\times$ 'Kotaro', 'Fuji' $\times$ 'Megumi', 'Fuji' $\times$ 'Orin', 'Fuji' $\times$ 'Tsugaru', 'Fuji' $\times$ Morioka 57, 'Kitaro' $\times$ 'Tsugaru', and 'Hatsuaki' $\times$ 'Megumi'); (B) seven crosses ('Fuji' $\times$ 'Himekami', 'Senshu' $\times$ 'Himekami', 'Fuji' $\times$ 'Akane', 'Kitaro' $\times$ 'Akane', 'Senshu' $\times$ 'Akane', 'Akane' $\times$ 'Megumi', and 'Akane' $\times$ 'Orin'); (C) nine crosses ('Fuji' $\times$ 'Sansa', 'Senshu' $\times$ 'Sansa', 'Fuji' $\times$ 'Starking Delicious' 'Sansa' $\times$ 'Shinsekai', 'Orin' $\times$ 'Sansa', 'Jonathan' $\times$ 'Sansa', 'Tsugaru' $\times$ 'Sansa', 'Jonathan' $\times$ 'Starking Delicious', and 'Tsugaru' $\times$ 'Starking Delicious'); (D) two crosses ('Sansa' $\times$ 'Akane' and 'Sansa' $\times$ 'Raritan'); and (E) one cross ('Sansa' $\times$ 'Starking Delicious'). The arrows indicate the degrees of mealiness of the parents.

where the softening rate of one parent on a cross was in a higher category, the distribution of softening in progenies shifted toward a higher rate (Fig. 2, B-D). The softening rates in nonmealy progenies from crosses between genotypes with softening rates of 0 to 1 and 1 to 2 were distributed around the midparent value, but the softening rates in mealy progenies from the same crosses were higher than the midparent value (Fig. 2B). For crosses of parents with a high softening rate, the proportion of mealy progenies with a high softening rate 

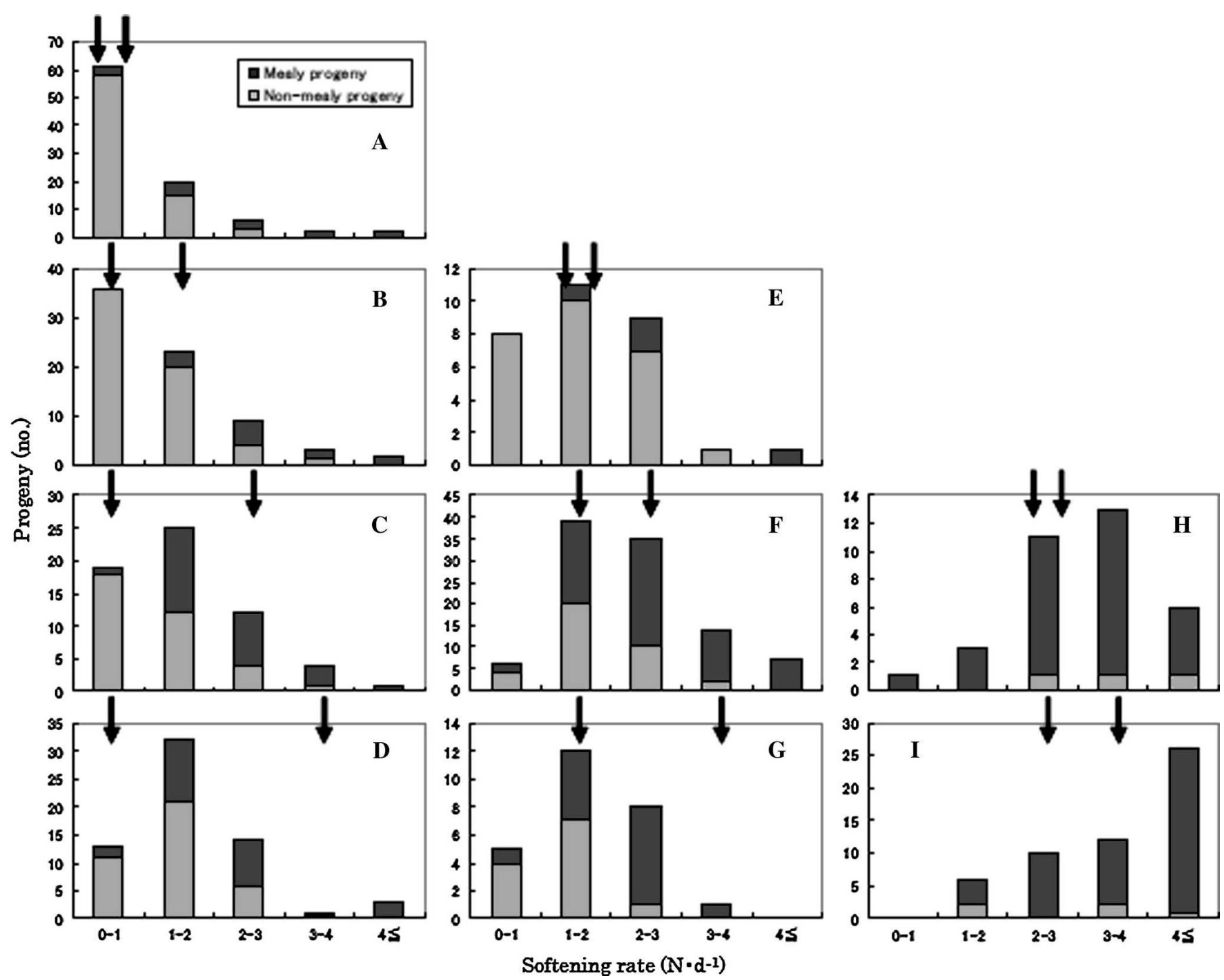

Fig. 2. Frequency distributions of softening rate under ambient conditions in 33 apple families in 2005. Families were classified into nine groups based on the softening rate of the parents. Each group consisted of progenies from (A) six crosses ('Fuji' $\times$ Morioka 54, 'Fuji' $\times$ 'Kotaro', 'Senshu' $\times$ Morioka 54, 'Kitaro' $\times$ 'Shinsekai', 'Senshu' $\times$ 'Shinsekai', 'and Senshu' $\times$ 'Kotaro'); (B) seven crosses ('Fuji' $\times$ 'Megumi', 'Fuji' $\times$ 'Orin', 'Fuji' $\times$ 'Tsugaru', 'Fuji' $\times$ Morioka 57, 'Kitaro' $\times$ 'Tsugaru', 'Toko' $\times$ Morioka 54, and 'Toko' $\times$ 'Kotaro'); (C) six crosses ('Fuji' $\times$ 'Sansa', 'Senshu' $\times$ 'Sansa', 'Fuji' $\times$ 'Starking Delicious', 'Fuji' $\times$ 'Himekami', 'Senshu' $\times$ 'Himekami', and 'Sansa' $\times$ 'Shinsekai'); (D) three crosses ('Fuji' $\times$ 'Akane', 'Kitaro' $\times$ 'Akane', and 'Senshu' $\times$ 'Akane'); (E) one cross ('Hatsuaki' $\times$ 'Megumi'); (F) five crosses ('Orin' $\times$ 'Sansa', 'Jonathan' $\times$ 'Sansa', 'Tsugaru' $\times$ 'Sansa', 'Jonathan' $\times$ 'Starking Delicious', and 'Tsugaru' $\times$ 'Starking Delicious'); (G) two crosses ('Akane' $\times$ 'Megumi' and 'Akane' $\times$ 'Orin'); (H) one cross ('Sansa' $\times$ 'Starking Delicious'); and (I) two crosses ('Sansa' $\times$ 'Akane' and 'Sansa' $\times$ 'Raritan'). The arrows indicate the softening rates of the parents.

increased (Fig. 2, E-I). In these families, the softening rates of nonmealy progenies tended to be lower than the midparent values, and the softening rates of mealy progenies tended to be higher than the midparent values. However, distinct segregation of the softening rate between nonmealy and mealy progenies was not observed in all families. Deviation of the softening rate of each progeny from the family mean was tested for normality using the Kolmogorov-Smirnov test, and a normal distribution was not rejected at $P=0.05$ in all families, notwithstanding if all progenies or only nonmealy progenies were used.

The relationships between the family mean and the midparent value showed almost the same trend among families that were sampled in 2004, 2005, and in both years. The regression of family mean on the midparent mean for softening rate showed that narrow-sense heritability $\left(\mathrm{h}^{2}\right)$, which was expressed as the regression coefficient, was high $(0.93 \pm$ 0.13 ) when all progenies were used for the estimation (Fig. $3 \mathrm{~A})$. When using only nonmealy progenies for the calculation of family mean, the regression coefficient was moderately high, $0.56 \pm 0.10$ (Fig. 3B).

The regression of the family mean of nonmealy progeny on the midparent cannot reveal the contribution of parents to the softening rate of nonmealy progenies because the midparent was calculated without discriminating between mealy and nonmealy genotypes. Therefore, the breeding values and the narrow-sense heritability for the softening rate of nonmealy progeny were estimated by sib analysis using the REML method. Before the analysis, the homogeneity of residual variances (within-family variances) was tested by Bartlett's test in addition to the above-mentioned test for normality. 


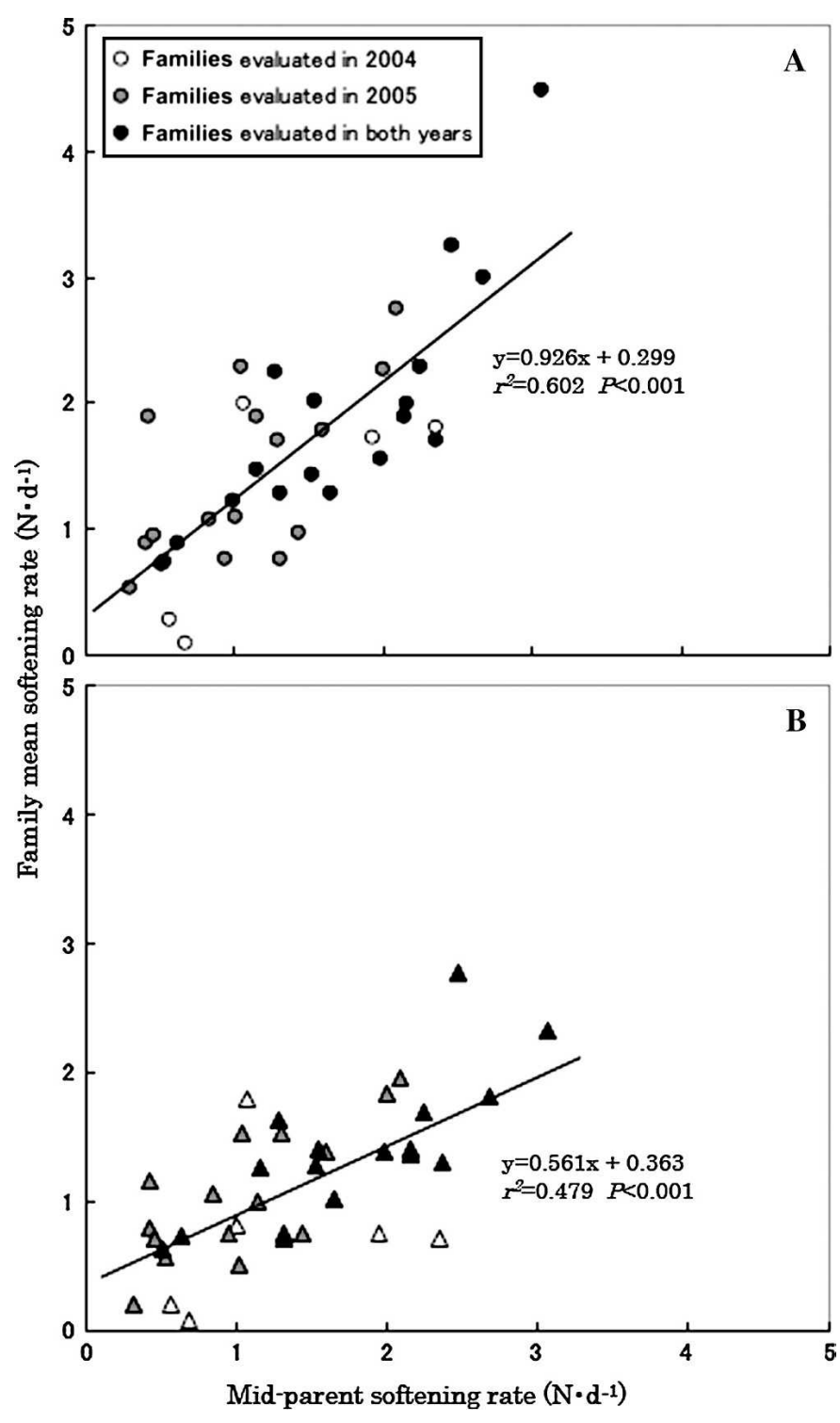

Fig. 3. Midparent-offspring regressions for softening rate based on (A) all progenies and (B) nonmealy progenies from 38 apple families.

No significant heterogeneity was detected $(P=0.132)$ when nonmealy progenies were used for the test, although significant heterogeneity was detected $(P<0.001)$ when mealy progenies were included. Therefore, the analyses using ANOVA and REML were assumed to be applicable to the nonmealy progeny data.

The effect of family on the softening rate of nonmealy progenies sampled in both years was highly significant $(P<$ 0.001 ), whereas the effects of year and year $\times$ family interaction were not significant $(P=0.482$ and 0.554 , respectively). A lack of year $\times$ family interaction indicates that the softening rate fluctuates uniformly in every family and the parental effect can be estimated reliably using data from different years by adjusting the yearly variation as a fixed effect.

The parental effect (GCA) was significant, but the interaction between parents (SCA) was small and nonsignificant when nonmealy progeny from all families were used (Table 3 ). The heritability $\left(h^{2}\right)$ estimated by sib analysis was $0.55 \pm$ 0.19 - almost identical to the heritability estimated by parentoffspring regression (0.56; Table 3 and Fig. 3B).
Table 3. Variance components based on restricted maximum likelihood (REML) and narrow sense heritability for softening rate using nonmealy progeny from 38 families in apple.

\begin{tabular}{llcr}
\hline Variance components & & Estimates & $P$ \\
\hline Parental effect (GCA) & $\sigma^{2}$ GCA & 0.1182 & 0.0133 \\
Parental interaction & & & \\
$\quad$ effect (SCA) & $\sigma^{2}$ SCA & 0.0549 & 0.0935 \\
Within family & $\sigma^{2}$ & 0.5759 & $<0.0001$ \\
Narrow-sense & & & \\
$\quad$ heritability & $h^{2}$ & $0.545 \pm 0.194$ \\
\hline
\end{tabular}

A significant correlation was observed between the softening rates (phenotypic values) of the parental genotypes and the breeding values (twice the GCA effects) estimated by BLUP methods $(P<0.001 ;$ Fig. 4$)$. The phenotypic values of nonmealy genotypes were highly and significantly correlated with the breeding values $(P=0.003)$. However, the phenotypic values of mealy genotypes did not significantly correlate with their breeding values $(P=0.310)$.

\section{Discussion}

Because knowledge of the modes of inheritance of agriculturally important traits can improve the breeding efficiency, there have been many studies on genetics of traits in apple. Major genes have been found for traits with simple inheritance patterns that show distinct segregation in the progenies (Brown, 1992). However, few studies have been published on the genetic parameters of quantitative traits, mainly because experimental data from major breeding programs were not suited for such estimations (Durel et al., 1998). Genetic parameter estimates have begun to be generated in apple for fruit traits, following developments in statistical tools and methods for analyzing unbalanced data, including REML and BLUP. For example, GCA and SCA estimates for ripening

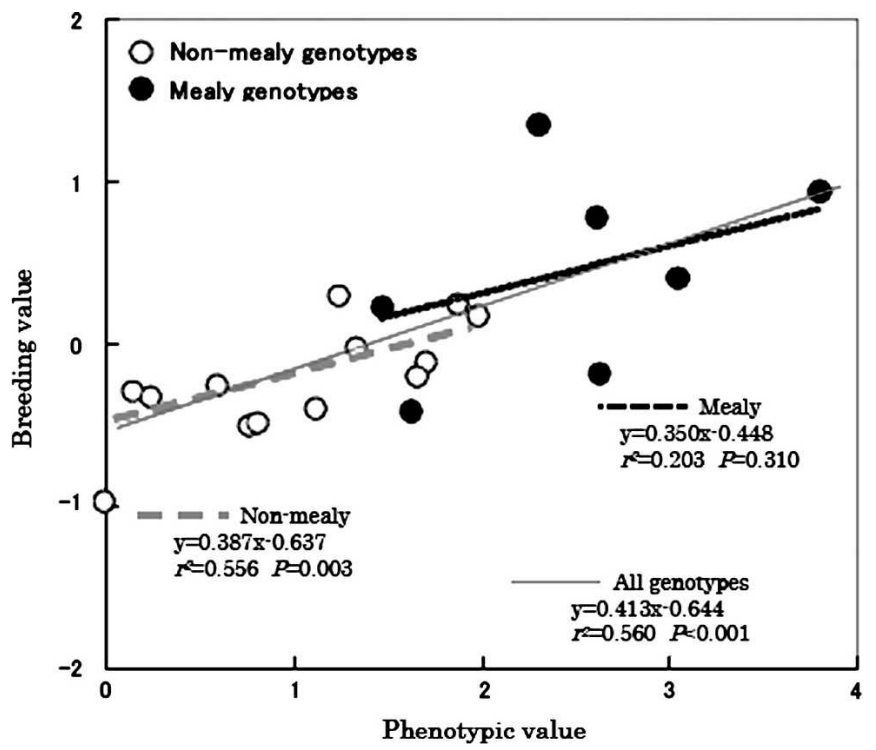

Fig. 4. The relationships between breeding value $(2 \times$ GCA $)$ and phenotypic value (softening rate, $\mathrm{N} \cdot \mathrm{d}^{-1}$ ) for softening in nonmealy, mealy, and all 20 parental apple genotypes. 
date (Tancred et al., 1995) and heritability and genetic correlations for fruit traits (Durel et al., 1998; Oraguzie et al., 2001, 2003).

The continuous distribution of softening rates of progeny around the midparent in each family is typical of a quantitative pattern of inheritance. On the other hand, noncontinuous segregation of the degree of mealiness was observed in the progeny populations despite being measured quantitatively (Fig. 1). When crossing between parents with a high and a low degree of mealiness, the progenies tended to be distributed not around the midparent value, but segregated to the extreme, i.e., below $10 \%$ and above $50 \%$ in the degree of mealiness at $30 \mathrm{~d}$ of storage. Therefore, progenies in which mealiness hardly occurred at $30 \mathrm{~d}$ of storage could be judged as nonmealy and qualitatively different from progenies with a high degree of mealiness at $30 \mathrm{~d}$ of storage.

Softening is a process primarily associated with the changes in the cell walls of parenchyma cells, which result in tissue failure. Tissue failure, which is observed when mechanical forces are applied to the flesh tissue, can be explained by three principal modes: cell fracture, cell rupture, and cell-to-cell debonding (cell separation; Harker et al., 1997). The ratio of the cells that fracture, rupture, and separate continuously changes according to the tissue conditions during storage (Harker et al., 2002, 2006). The method used in our study for measuring mealiness can only detect the contribution of cell separation to tissue failure (cell-to-cell bonding). Cell fracture and cell rupture could also occur, and the contributions of those to tissue failure could continuously change, irrespective of the occurrence of mealiness (cell separation). In this study, the softening rates of mealy progenies tended to be higher than those of nonmealy progenies and were distributed relatively widely (Fig. 2). Therefore, the softening rates were continuously distributed in every family when mealy and nonmealy progenies were combined, although Iwanami et al. (2005b) observed that the softening rates of mealy genotypes were all high, with about the same values.

The heritability estimated using data from all progenies was high, at 0.93 (Fig. 3A). Although the estimate of the heritability depends on the population tested, the environmental circumstances to which the individuals are subjected, and the way in which the phenotype is measured (Falconer and Mackay, 1996), the heritability of the ripening date of apple was also reported to be high $\left(h^{2}=0.94\right.$ by Tancred et al., $1995 ; h^{2}=0.6$ to 0.9 by Oraguzie et al., 2003). Ripening date is not usually a trait highly selected for in fruit breeding. Early, middle-, and lateripening cultivars are all useful and desirable for growers because cultivars with various ripening dates can help spread the harvest. Therefore, the ripening date of parents used in fruit breeding has a wide range, thus contributing to the high heritability for this trait in many crops. For example, it is 0.87 to 1.0 in japanese pear (Pyrus pyrifolia Nakai; Abe et al., 1993), 0.94 and 0.84 in peach (de Souza et al., 1998 and Hansche et al., 1972, respectively), 0.99 in persimmon (Diospyros kaki Thunb.; Yamada et al., 1995), and 0.88 in sweet cherry (Hansche et al., 1966). The high heritability for the softening rate in our study also suggests that little selection has been applied to this trait in apple, and genetic diversity is considered to be large regarding the softening rate.

On the other hand, the heritability estimated by sib analysis using data from nonmealy progenies was moderately high, at 0.55 , but lower than that estimated using all progenies (Table
3). The family means for the softening rate of nonmealy progeny were lower than those for all progeny in every family (Fig. 3). The lower variation of the family mean could raise the magnitude of environmental variance, resulting in lower heritability. Alspach and Oraguzie (2002) estimated the heritability of fruit traits in apple, with the estimates generally low and varying between 0.1 and 0.6 . They suggested that the magnitude of environmental variance caused by the yearly effect in each fruit trait could have contributed to the low and differing heritability estimates.

To produce progeny with good storage potential or shelf life, it is necessary to predict the softening rate in the nonmealy progeny of the next generation from the phenotype of the present genotypes used as parents. However, the softening rate as the phenotype value in mealy parents was biased by the occurrence of mealiness and was not expected to be a good predictor. Therefore, the breeding value that expressed the contribution of mealy parents to the softening rate of nonmealy progeny was estimated by sib analysis using nonmealy progenies. Because year $\times$ family interaction was not significant, sib analysis was performed using 2 years of data combined. The lack of interaction could be attributed to the softening rates of individual progenies not being significantly different from year to year. This observation was consistent with the results of Iwanami et al. (2005a), which showed that the softening rate, represented by a linear regression coefficient, was stable against environmental conditions.

The variance of the SCA was not significant and was small (Table 3). This result indicates that the family means of the softening rate in the nonmealy progeny of future crosses within the parental set used in this study can be readily predicted by GCA estimates alone. Moreover, a significant correlation was observed between the phenotypic values and the breeding values of the parental genotypes (Fig. 4). This correlation indicates that genotypes with a high softening rate will tend to produce progenies with a high softening rate, irrespective of occurrence of mealiness. The reason that the heritability estimated by sib analysis was almost the same as that estimated by parent-offspring regression (Table 3 and Fig. 3B) could be because the phenotypic value and the breeding value were significantly correlated, although the softening rates of mealy parents were expected to be quite high. On the other hand, the softening rate of mealy genotypes was not significantly correlated with the breeding value (Fig. 4). Moreover, softening rates and breeding values showed wide variations in mealy genotypes. In our study, two-thirds of parental genotypes were nonmealy and resulted in the significant correlation between phenotypic values and breeding values of all parental genotypes. When many mealy genotypes have been used for breeding programs, a significant correlation would not have been observed between the phenotypic values and the breeding values. In Japan, many nonmealy cultivars have been produced, particularly from 'Fuji' or other nonmealy cultivars because Japanese consumers are very sensitive to the mealy texture of apples (Iwanami et al., 2005b). Therefore, nonmealy cultivars will be exclusively used for breeding programs in Japan, with the result that the breeding values of parental cultivars could be evaluated based on their phenotypic values. Finn and Luby (1992) also observed low correlation between breeding values (GCA) and parental phenotype scores for fruit color, picking scar, and firmness in a population of blueberry from interspecific crossings. 
In conclusion, the softening rates in the progeny populations were distributed continuously around the softening rates of parents, although segregation of the degree of mealiness at $30 \mathrm{~d}$ of storage was observed. The heritability estimate of the softening rate was high, suggesting that storage and shelf life traits have been sparingly characterized and selected for in breeding programs. This also means that selection of a parent based on its softening rate can contribute to the improvement of softening rate in the next generation. The variance of the SCA was small and nonsignificant, indicating that the family means of nonmealy progeny of future crosses within the parental set used in this study can be readily predicted from GCA estimates alone. Moreover, a significant correlation was observed between the phenotypic values and the breeding values of the parental genotypes. However, the softening rate of mealy genotypes was not significantly correlated with the breeding value, indicating that contribution of a mealy genotype to the softening rate of nonmealy progenies cannot be predicted by its phenotypic value.

\section{Literature Cited}

Abe, K., Y. Sato, T. Saito, A. Kurihara, and K. Kotobuki. 1993. Inheritance of ripening time of fruit of Japanese pear (Pyrus pyrifolia Nakai). Jpn. J. Breeding 43:289-298.

Alspach, P.A. and N.C. Oraguzie. 2002. Estimation of genetic parameters of apple (Malus domestica) fruit quality from openpollinated families. N.Z. J. Crop Hort. Sci. 30:219-228.

Brown, S.K. 1992. Genetics of apple. Plant Breed. Rev. 9:333-366.

Daoyu, Z., G.S. Lawes, and I.L. Gordon. 2002. Estimates of genetic variability and heritability for vegetative and reproductive characters of kiwifruit (Actinidia deliciosa). Euphytica 124:93-98.

de Souza, V.A.B., D.H. Byrne, and J.F. Taylor. 1998. Heritability, genetic and phenotypic correlations, and predicted selection response of quantitative traits in peach: II. An analysis of several fruit traits. J. Amer. Soc. Hort. Sci. 123:604-611.

Durel, C.E., F. Laurens, A. Fouillet, and Y. Lespinasse. 1998. Utilization of pedigree information to estimate genetic parameters from large unbalanced data sets in apple. Theor. Appl. Genet. 96:10771085.

Falconer, D.S. and T.F.C. Mackay. 1996. Introduction to quantitative genetics. 4th ed. Longman, London.

Finn, C.E. and J.J. Luby. 1992. Inheritance of fruit quality traits in blueberry. J. Amer. Soc. Hort. Sci. 117:617-621.

Firoozabady, E. and H.P. Olmo. 1987. Heritability and correlation studies of certain quantitative traits in table grapes, Vitis spp. Vitis 26:132-146.

Hampson, C.R. and H. Kemp. 2003. Characteristics of important commercial apple cultivars, p. 61-89. In: D.C. Ferree and I.J. Warrington (eds.). Apple. CABI Publishing, Wallingford, UK.

Hansche, P.E., V. Beres, and R.M. Brooks. 1966. Heritability and genetic correlation in the sweet cherry. J. Amer. Soc. Hort. Sci. 88:173-183.

Hansche, P.E., C.O. Hasse, and V. Beres. 1972. Estimates of genetic and environmental effects on several traits in peach. J. Amer. Soc. Hort. Sci. 97:76-79.
Harker, F.R., J. Maindonald, S.H. Murray, F.A. Gunson, I.C. Hallett, and S.B. Walker. 2002. Sensory interpretation of instrumental measurements. 1: Texture of apple fruit. Postharvest Biol. Technol. 24:225-239.

Harker, F.R., R.J. Redgwell, I.C. Hallett, S.H. Murray, and G. Carter. 1997. Texture of fresh fruit, p. 121-124. In: J. Janick (ed.). Horticultural Reviews, vol. 20. Wiley, New York.

Harker, F.R., A. White, F.A. Gunson, I.C. Hallett, and H.N. De Silva. 2006. Instrumental measurement of apple texture: A comparison of the single-edge notched bend test and the penetrometer. Postharvest Biol. Technol. 39:185-192.

Iwanami, H., M. Ishiguro, N. Kotoda, S. Takahashi, and J. Soejima. 2004. Evaluation of differences in softening of apple genotypes by linear regression. HortScience 39:1185-1188.

Iwanami, H., M. Ishiguro, N. Kotoda, S. Takahashi, and J. Soejima. 2005a. Optimal sampling strategies for evaluating fruit softening after harvest in apple breeding. Euphytica 144:169-175.

Iwanami, H., S. Moriya, N. Kotoda, S. Takahashi, and K. Abe. 2005 b. Influence of mealiness on the firmness of apples after harvest. HortScience 40:2091-2095.

Johnston, J.W., E.W. Hewett, and M.L.A.T.M. Hertog. 2002a. Postharvest softening of apple (Malus domestica) fruit: A review. N.Z. J. Crop Hort. Sci. 30:145-160.

Johnston, J.W., E.W. Hewett, M.L.A.T.M. Hertog, and F.R. Harker. 2001. Temperature induces differential softening responses in apple cultivars. Postharvest Biol. Technol. 23:185-196.

Johnston, J.W., E.W. Hewett, M.L.A.T.M. Hertog, and F.R. Harker. 2002b. Temperature and ethylene affect induction of rapid softening in 'Granny Smith' and 'Pacific Rose' apple cultivars. Postharvest Biol. Technol. 25:257-264.

Oraguzie, N.C., M.E. Hofstee, L.R. Brewer, and C. Howard. 2001. Estimation of genetic parameters in a recurrent selection program in apple. Euphytica 118:29-37.

Oraguzie, N.C., C. Whitworth, P.A. Alspach, C.G.T. Morgan, and J. Fraser. 2003. First generation of recurrent selection in apple: Estimation of genetic parameters. Acta Hort. 622:213-220.

Rumpunen, K. and D. Kviklys. 2003. Combining ability and patterns of inheritance for plant and fruit traits in Japanese quince (Chaenomeles japonica). Euphytica 132:139-149.

Tancred, S.J., A.G. Zeppa, M. Cooper, and J.K. Stringer. 1995. Heritability and patterns of inheritance of the ripening date of apples. HortScience 30:325-328.

Tong, C., D. Krueger, Z. Vickers, D. Bedford, J. Luby, A. El-Shiekh, K. Shackel, and H. Ahmadi. 1999. Comparison of softening-related changes during storage of 'Honeycrisp' apple, its parent, and 'Delicious'. J. Amer. Soc. Hort. Sci. 124:407-415.

Volz, R.K., P.A. Alspach, A.G. White, and I.B. Ferguson. 2001. Genetic variability in apple fruit storage disorders. Acta Hort. 553:241-244.

Xiang, B. and B. Li. 2001. A new mixed analytical method for genetic analysis of diallel data. Can. J. For. Res. 31:2252-2259.

Yamada, M., H. Yamane, and Y. Ukai. 1995. Genetic analysis of fruit ripening time in Japanese persimmon. J. Amer. Soc. Hort. Sci. 120:886-890.

Yoshida, Y., X. Fan, and M. Patterson. 1998. The 'Fuji' apple, p. 137141. In: D.C. Ferree (ed.). A history of fruit varieties. Good Fruit Grower Magazine, Yakima, WA. 